\title{
AVALIAÇÃO DOS CONCEITOS DE PRODUÇÃO INTEGRADA DE FRUTAS À PRODUÇÃO DE MAÇA NA REGIÃO CENTRO SUL DO PARANÁ
}

\section{EVALUATION OF THE CONCEPTS OF INTEGRATED PRODUCTION OF FRUITS TO THE APPLE PRODUCTION IN THE REGION SOUTH CENTER OF THE PARANÁ}

\author{
Kellen Cristiane Ribeiro da Rocha ${ }^{1 ;}$ Suzana Helena Vogelaar ${ }^{2}$; José Mauro Giroto ${ }^{3}$ \\ ${ }^{1,2,3}$ Universidade Tecnológica Federal do Paraná - UTFPR - Ponta Grossa - Brasil \\ ke_rocha@yahoo.com.br
}

\begin{abstract}
Resumo:
A pomicultura é uma atividade relativamente recente no Brasil. Iniciou-se na década de 70 por meio de incentivos fiscais e apoio à pesquisa e extensão rural. Atualmente, o mercado mundial de consumo de maçã "in natura" vem apresentando uma preferência por consumir frutas com boa aparência, tamanho e uniformidade além de outros aspectos ligados às características organolépticas, à segurança alimentar, a proteção ao meio ambiente e rastreabilidade. Por esse motivo, o INMETRO em conjunto com o Ministério de Agricultura, Pecuária e Abastecimento (MAPA), desenvolveu um Programa da Avaliação da Conformidade, ou seja, um programa voluntário que gera frutas de alta qualidade, priorizando a sustentabilidade, a aplicação de recursos naturais, a substituição de insumos poluentes, o monitoramento dos procedimentos e a rastreabilidade de todo o processo do programa, tornando-o economicamente viável, ambientalmente correto e socialmente justo. Este trabalho relata a situação de cadeia produtiva da maçã no município de Porto Amazonas no estado do Paraná. Após a tabulação dos dados pode-se concluir que existe uma grande diferença entre os produtores com relação à implantação da Produção Integrada de Maçã (PIM), constatando que o produtor do pomar A é o que mais está em conformidade para certificação de Produção Integrada de Maçã. Os produtores $B$ e C, ainda não estão aptos para serem inseridos no conceito de Produção Integrada de Frutas.
\end{abstract}

Palavras-chave: maçã, consumidor, rastreabilidade, segurança alimentar e produção integrada.

\section{Introdução}

A fruticultura compreende um segmento do mercado que guarda particularidades em relação aos demais setores agrícolas. Essas especificidades tornam-se mais evidentes quando a análise é centrada no consumo in natura, uma vez que, como produtos perecíveis, exigem complexa estrutura logística capaz de garantir a produção e a distribuição com prazos, qualidade e preços competitivos. (SANHUEZA; HOFFMANN, 2008). A fruticultura é apontada como uma atividade promissora 
para o desenvolvimento do setor agrícola brasileiro, apresentando um ambiente favorável ao seu crescimento (PAULINO; JACOMETI, 2008).

Vários são os modelos para a produção de frutas e os mais representativos são a produção orgânica e a convencional. Um outro modelo tem despertado a atenção e utilizado em diversas produções de frutas denominado Produção Integrada de Frutas (PIF). Este modelo é um Programa de Avaliação da Conformidade voluntário, desenvolvido pelo (INMETRO) Instituto Nacional de Metrologia, Normalização e Qualidade Industrial em conjunto com o (MAPA) Ministério de Agricultura, Pecuária e Abastecimento, com o objetivo de produzir frutas de alta qualidade, onde prioriza a sustentabilidade, a aplicação de recursos naturais, a substituição de insumos poluentes, o monitoramento dos procedimentos de produção e a rastreabilidade de todo o processo produtivo, tornando-o economicamente viável, ambientalmente correto e socialmente justo (INMETRO, 2009).

A PIF teve um grande impulso a partir dos anos 80 e 90 em função do movimento de consumidores que buscavam frutas sadias, com qualidade e sem resíduos de agroquímicos e do trabalho de pesquisadores e extensionistas que estimularam os movimentos para preservação dos recursos naturais e a biodiversidade (UFPEL, 2009).

Atualmente, a Produção Integrada de Frutas (PIF) encontra-se presente em países produtores de maçãs na Europa. A fruta obtida na PIF é comercializada após sua certificação, identificada por um selo, e sua compra é a preferida pelos grandes canais de comercialização. Os principais países produtores da Europa, Austrália, Nova Zelândia e África do Sul têm o sistema de Produção Integrada em funcionamento, especialmente para maçãs, outras frutas de clima temperado e para alguns produtos derivados tais como o vinho. Esta estratégia de produção também está sendo implementada para hortaliças e cereais (OLIVEIRA, 2009).

No início da década de 70, a produção anual de maçãs era de cerca de 1.000 toneladas. Com incentivos fiscais e apoio à pesquisa e extensão rural, o Sul do Brasil aumentou a produção de maçãs em quantidade e em qualidade, fazendo com que o país passasse de importador a exportação (SANHUEZA, 2003; FERREIRA, 2009).

De acordo com a Associação Brasileira de Produtores de Maçã (ABPM), em 2003, as normas da PIF, no caso da maçã, Produção Integrada da Maçã (PIM), foram implantas no Brasil em 13.500 hectares de pomares, com parte da produção dirigida ao mercado externo. Em 2004, mais 2.500 hectares foram incorporados e novas áreas estão em fase de preparação para a adequação. Isso significa que, em quase 50\% da área cultivada com macieira no Brasil, já foram implantadas as normas da PIM (BRDE, 2005).

O objetivo geral deste trabalho foi avaliar por meio de uma lista de verificação estabelecida pelo Ministério da Agricultura Pecuária e Abastecimento, o atendimento aos requisitos 
estabelecidos para a Produção Integrada de Frutas (PIF) na produção de maçã na região centro sul do estado do Paraná.

\section{Material e métodos}

Para a realização do presente trabalho foram realizadas as seguintes etapas: Como primeira etapa do trabalho realizou-se uma revisão na literatura quanto aos conceitos relacionados á produção integrada. Após esta revisão identificaram-se os requisitos necessários à implantação deste modelo por meio de Normas Técnicas Específicas para a Produção Integrada de Maçã (NTEPI - Maçã) estabelecida pelo Ministério da Agricultura Pecuária e Abastecimento. Identificação dos mecanismos de classificação e certificação da produção (Lista de Verificação para Auditoria de Acompanhamento - Campo e Lista de Verificação para Auditoria de Acompanhamento - Póscolheita), estabelecido pelo MAPA (Ministério da Agricultura Pecuária e Abastecimento). Identificação dos produtores de maçã na região Centro Sul, por meio dos órgãos de fomento à produção de frutas do Estado. Visita aos produtores para conhecimento do material e ambiente de estudo (produtores e responsáveis técnicos). Convite aos produtores e responsáveis técnicos para participação na pesquisa. Apresentação do modelo da lista de verificação para auditoria aos produtores e responsáveis técnicos. Aplicação da lista de verificação para auditoria aos produtores da região Centro Sul do Estado do Paraná. Tabulação e apresentação dos dados obtidos.

\section{Resultados e discussão}

O mercado consumidor nacional e internacional de alimentos busca cada vez mais, garantia de qualidade e segurança alimentar. Esse fato se traduz na necessidade de adoção de práticas que assegurem a qualidade exigida por esses mercados e o atendimento a normas de segurança. Além da qualidade e da segurança dos alimentos é necessário que os sistemas produtivos atendam às legislações ambientais e trabalhistas, proporcionando um modelo de produção economicamente viável e socialmente justo (SILVEIRA, 2006).

O conceito de Produção Integrada foi criado na Europa na década de 70. Naquela época os produtores de maçãs do Norte da Itália verificaram que os ácaros da macieira tinham adquirido resistência aos acaricidas. Em função disso, e com auxilio de pesquisadores, iniciaram um programa de manejo integrado de ácaros, usando monitoramento e técnicas alternativas de controle. Posteriormente foi verificado que o problema dos ácaros perdeu importância e os produtores voltaram aos velhos costumes. Manifestaram-se nos círculos científicos preocupações quanto ao alcance restrito do manejo integrado de pragas, como estratégia utilizada para racionalização e redução de uso de agroquímicos e de sustentabilidade da atividade frutícola. Em conjunto decidiram 
que deveria haver mudanças profundas em todo o sistema e que as práticas isoladas para o controle de uma praga ou doença não eram suficientes, era necessário, portanto, uma integração com as demais práticas culturais, assim foram dados os primeiros passos para o estabelecimento das bases para a Produção Integrada de Frutas (PIF) (SANHUEZA, 2008; UFPEL, 2009).

Para delineamento da proposta do programa de produção integrada de frutas, criou-se grupos de trabalho, com especialistas de diferentes países, visando obter a definição, alcance e organização dos Sistemas de Produção Integrada de Frutas. Assim, em 1989, estabeleceu-se um regulamento e este foi aceito e reconhecido pela Organização Internacional de Luta Biológica de pragas (IOBC) (SANHUEZA, 2008).

A Organização Internacional para Controle Biológico e Integrado contra os Animais e Plantas Nocivas (OILB) define a Produção Integrada como “o sistema de produção que gera alimentos e demais produtos de alta qualidade, mediante a aplicação de recursos naturais e regulação de mecanismos para a substituição de insumos poluentes e a garantia da sustentabilidade da produção agrícola; enfatiza o enfoque do sistema holístico, envolvendo a totalidade ambiental como unidade básica; o papel central do agro-ecossistema; o equilíbrio do ciclo de nutrientes; a preservação e o desenvolvimento da fertilidade do solo e a diversidade ambiental como componentes essenciais; e métodos e técnicas biológico e químico cuidadosamente equilibrado, levando-se em conta a proteção ambiental, o retorno econômico e os requisitos sociais” (BRASIL, 2002).

No Brasil, os primeiros trabalhos foram iniciados na Embrapa Uva e Vinho, em 1996, através de uma discussão interna sobre as abordagens mais adequadas a serem seguidas para dar condições para a implementação do sistema. Posteriormente, a informação foi discutida com técnicos de pesquisa e assistência técnica publica e privada, vinculados diretamente à produção de maçãs e, posteriormente, apresentada para discussão e avaliação com os representantes dos produtores (SANHUEZA, 2008).

A Produção Integrada de Frutas - PIF é um Programa de Avaliação da Conformidade voluntário, desenvolvido pelo INMETRO em conjunto com o Ministério de Agricultura, Pecuária e Abastecimento (MAPA), que gera frutas de alta qualidade, priorizando a sustentabilidade, a aplicação de recursos naturais, a substituição de insumos poluentes, o monitoramento dos procedimentos e a rastreabilidade de todo o processo do programa, tornando-o economicamente viável, ambientalmente correto e socialmente justo. O principal objetivo da PIF é substituir as práticas convencionais onerosas por um processo que possibilite a diminuição dos custos de produção, melhoria da qualidade, redução dos danos ambientais e aumento do grau de credibilidade e confiabilidade do consumidor em relação às frutas brasileiras (INMETRO, 2009). 
Para a implementação deste programa foram tomados como base o manejo integrado de pragas e o APPCC (Avaliação de Perigo e Pontos Críticos de Controle), conhecido mundialmente pela sigla HACCP. A PIF é uma resposta ao EurepGAP, hoje Global-GAP, um certificado que garante padrão de produção e segurança alimentar, criado por 35 redes de supermercados europeus, a qual vem ao encontro do desejo do consumidor que quer um produto seguro para o consumo e produzido em harmonia com o meio ambiente (BRDE, 2005).

A representação deste modelo é apresentado na Figura 1. Pode-se observar que o modelo está colocada no ápice da pirâmide como o nível mais elevado, demonstrando que é um sistema organizado tecnológica num contexto em que os patamares para inovação e competitividade são estratificados por níveis de desenvolvimento (ANDRIGUETO e KOSOSKI, 2003).

Figura 1 - Patamares para a inovação e competitividade na fruticultura brasileira

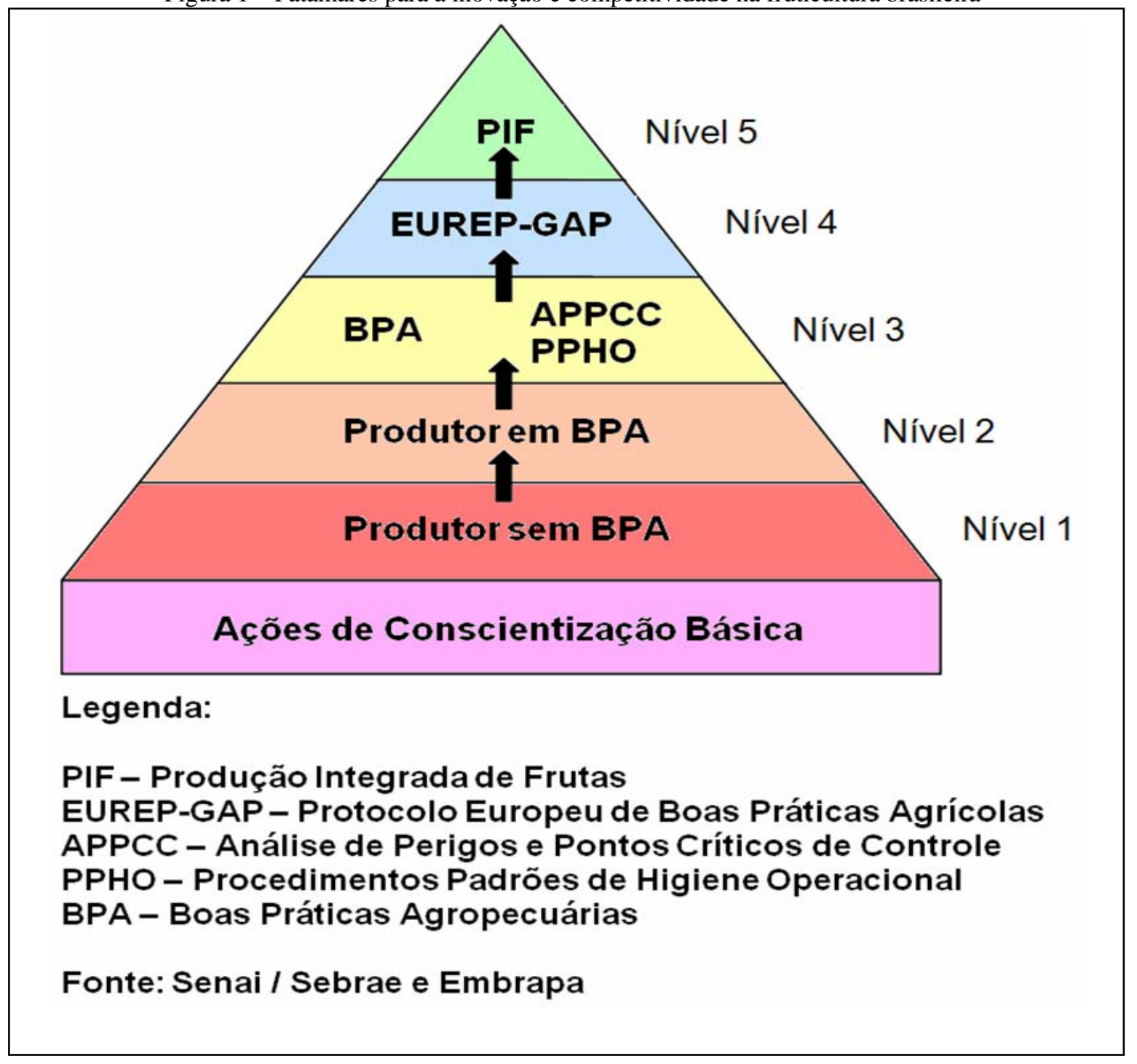

O sistema permite rastrear toda a cadeia, desde as áreas de cultivo até a mesa do consumidor. No caso específico da maçã, de acordo com dados do Ministério da Agricultura, houve 
uma significativa redução de herbicidas em 67\%, o de acaricidas, 67\%; o de inseticidas, 25\%; e o de fungicidas em 15\% (BRASIL, 2007).

O marco legal para este modelo de produção já existe no País, composto de Diretrizes Gerais e Normas Técnicas Gerais para a Produção Integrada de Frutas oficializada por intermédio da Instrução Normativa N 20, publicada no Diário Oficial da União-DOU, no dia 15 de outubro de 2001, na qual há o Regulamento de Avaliação da Conformidade-RAC, Definições e Conceitos-PIF, Regimento Interno da Comissão Técnica-CTPIF, Formulários de Cadastro-CNPE e outros componentes de igual importância (BRASIL, 2002).

O sistema possui um arcabouço técnico operacional de suporte o qual é composto por Normas Técnicas Específicas-NTE, para todas as frutas (15 Áreas Temáticas), Grade de Agroquímicos, Cadernos de Campo e Pós-Colheita e Listas de Verificação de Campo e Empacotadora (BRASIL, 2002).

As Normas Técnicas Gerais para a Produção Integrada de Frutas - NTGPIF, contemplam as seguintes áreas temáticas: Capacitação de Recursos Humanos; Organização de Produtores; Recursos Naturais; Material Propagativo; Implantação de Pomares; Nutrição de Plantas; Manejo e Conservação do Solo; Recursos Hídricos e Irrigação; Manejo da Parte Aérea; Proteção Integrada da Planta; Colheita e Pós-colheita; Análise de Resíduos; Processo de Empacotadoras; Sistema de Rastreabilidade e Cadernos de Campo; Assistência Técnica (BRASIL, 2002).

Os preceitos das Normas Técnicas Gerais para a Produção Integrada de Frutas - NTGPIF, são classificados em “obrigatórios”, “recomendados”, “proibidos” e "permitidos com restrição” para cada uma das áreas temáticas indicadas, constituindo-se em referências básicas necessárias ao processo de elaboração das Normas Técnicas Específicas - NTE e da Grade de Agroquímicos para cada cultura e região produtora (BRASIL, 2006).

Os componentes destes documentos são objetos para a Avaliação da Conformidade, utilizados pelos Organismos de Avaliação da Conformidade - Certificadoras - acreditados pelo INMETRO, o qual é membro do International Accreditation Forum - IAF (ANDRIGUETO et al, 2009).

Quanto ao conceito de rastreabilidade, os procedimentos básicos neste modelo são estabelecidos utilizando-se das seguintes informações: divisão da área produtiva em talhões ou parcelas; registro nos cadernos de campo e de pós-colheita; identificação da unidade de colheita no pomar através de etiquetas contendo informações do local, do produtor, do processo produtivo e outras; processamento das frutas em lotes homogêneos; adoção de logística no campo e na empacotadora ou indústria, capaz de manter a identidade dos lotes dentro do sistema, garantindo a identificação do produto até o consumidor (ANDRIGUETO et al, 2009). 
A adoção do Sistema de Produção Integrada de Frutas-PIF evoluiu em curto espaço de tempo, tomando conta de muitas áreas existentes em países tradicionais de produção de frutas. Na América do Sul, a Argentina foi o primeiro país a implantar o modelo em 1997, seguindo-se no mesmo ano, o Uruguai e o Chile. Atividades semelhantes deram início nos anos de 1998/99 mo Brasil (ANDRIGUETO, KOSOSKI, 2005).

O Brasil iniciou em 1998 a implantação deste modelo de produção com a cultura da maçã em Vacaria-RS e Fraiburgo- SC, devido ao fato de que os produtores e as empresas envolvidas na exportação de maçãs constataram que sem um programa de produção integrada ficariam fora do mercado internacional. Posteriormente, outras regiões do país iniciaram a implantação deste programa, com destaque para o Vale do São Francisco, com as culturas da manga e uva. (OLIVEIRA, 2009).

A Tabela 1 ilustra as diferenças entre a Produção Integrada e a Produção Convencional, demonstrando as principais diferenças entre os modelos.

Tabela 1 - Comparação entre a Produção Integrada (PI) e a Produção Convencional (PC).

\begin{tabular}{|c|c|}
\hline $\begin{array}{l}\text { Opção por adesão em documento assinado com a } \\
\text { certificadora }\end{array}$ & Não há \\
\hline Treinamento e atualização técnica obrigatória & $\begin{array}{l}\text { Treinamento e atualização técnica } \\
\text { opcional }\end{array}$ \\
\hline $\begin{array}{c}\text { Práticas usadas para o manejo do pomar referidas } \\
\text { nas Normas Técnicas da PI }\end{array}$ & $\begin{array}{l}\text { Práticas de manejo da cultura usadas } \\
\text { parcialmente e sem restrições (Sistema de } \\
\text { produção) }\end{array}$ \\
\hline $\begin{array}{l}\text { Restrições ao uso de agroquímicos com impacto } \\
\text { ambiental indesejável e/ou com potencial de } \\
\text { eliminação de organismos benéficos }\end{array}$ & $\begin{array}{c}\text { Restrições ao uso de pesticidas, baseadas } \\
\text { nos riscos toxicológicos, e sobre fauna } \\
\text { nativa } \\
\text { Não considera fertilizantes }\end{array}$ \\
\hline Controle durante o ciclo todo & Controle somente na comercialização \\
\hline $\begin{array}{l}\text { Comercialização de produtos com selo de garantia e } \\
\text { rastreabilidade }\end{array}$ & $\begin{array}{l}\text { Não inclui obrigatoriamente a } \\
\text { rastreabilidade }\end{array}$ \\
\hline
\end{tabular}

Fonte: SANHUEZA; HOFFMANN, 2008

A produção mundial de frutas está em torno de 540,0 milhões de t, correspondendo ao montante de US\$162,0 bilhões. O Brasil, depois da China e Índia, é o $3^{\circ}$ maior produtor de frutas do mundo (ANDRIGUETO e KOSOSKI, 2005) e de acordo com FERREIRA (2009), a produção de maçãs no Brasil nas últimas três décadas teve um impressionante aumento de mais de 6.000\%. De importador o País passou não apenas a abastecer todo o mercado interno, como também a exportar $15 \%$ de sua colheita. O investimento em pesquisas teve papel fundamental nesse resultado.

No Paraná, de acordo com o IBGE, a macieira é cultivada, principalmente, nas mesorregiões centro-sul paranaense e metropolitana de Curitiba. Mesmo com uma escala de produção modesta em relação às demais regiões produtoras, a maçã tem importância fundamental no agronegócio dos municípios em que está inserida. O vigor do segmento é nítido, as regiões produtoras possuem boa 
infra-estrutura de classificação e armazenagem. Além disso, os pomicultores paranaenses possuem vantagem comparativa, pois a colheita, principalmente da cultivar Eva, se inicia antecipadamente às produções das principais regiões do País. A Associação dos Fruticultores do Paraná (Frutipar), a qual estão associados 35 produtores, inclusive de outras frutas (pêra, pêssego, kiwi, etc.), representa os produtores de maçã do Estado (BRDE, 2005). A Figura 2 ilustra as principais regiões produtoras do Estado do Paraná.

Figura 2 - Principais regiões produtoras de maça no Estado do Paraná

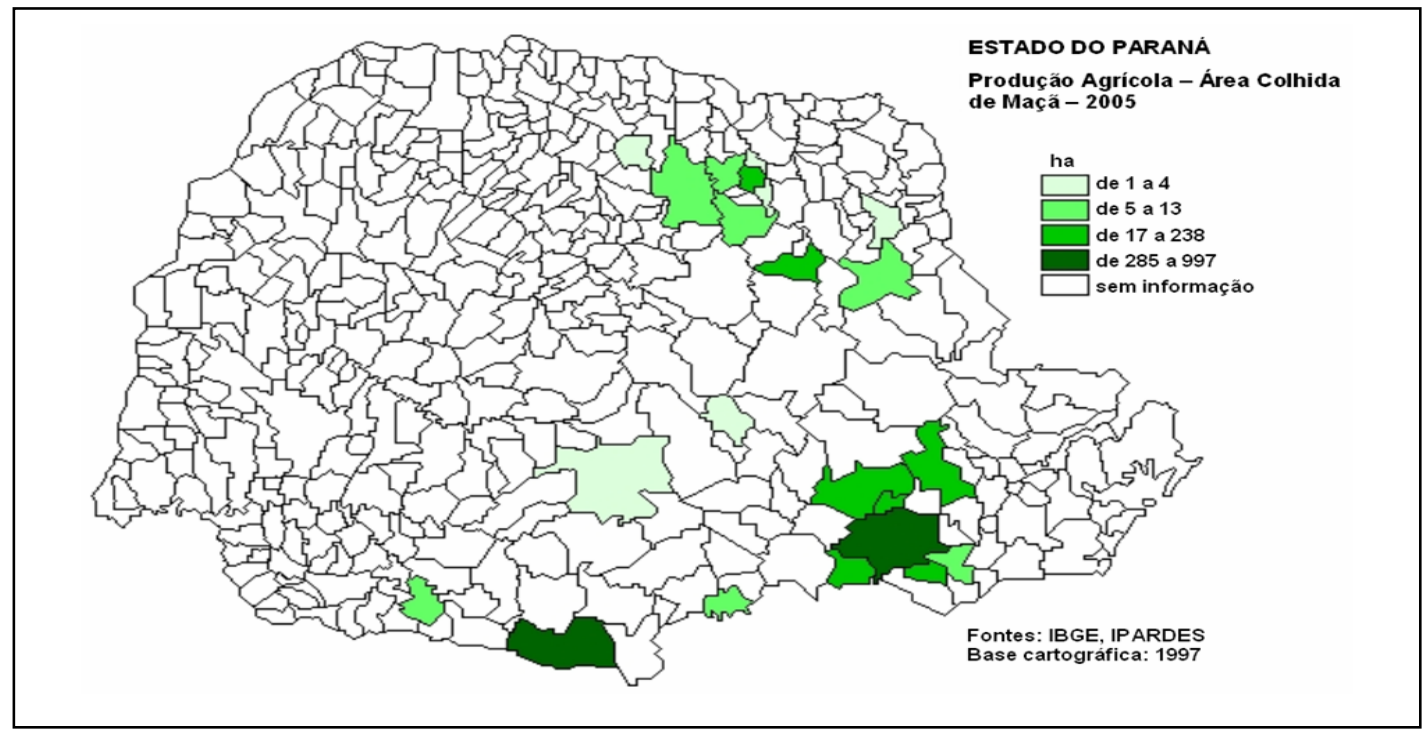

Como pode ser visualizado na Figura 2, o pólo produtor de maçã no Paraná está concentrado principalmente entre as cidades de Porto Amazonas, Campo do Tenente e Lapa. Palmas também tem produção considerável, mas não se diferencia como essas três cidades, que concentram uma peculiaridade: são as únicas onde a fruta é colhida na entressafra, ou seja, em janeiro, um mês antes das colheitas dos maiores produtores do País, os estados do Rio Grande do Sul e Santa Catarina (MARTONI, 2008).

O processo de Avaliação da Conformidade da Produção Integrada de Frutas é sustentado pelos modelos definidos no âmbito do Sistema Nacional de Metrologia, Normalização e Qualidade Industrial - SINMETRO, além dos preceitos estabelecidos nas Diretrizes Gerais para a Produção Integrada de Frutas, nas Normas Técnicas Específicas para a Produção Integrada de Frutas e nos princípios, diretrizes e técnicas preconizados pela Organização Internacional para Controle Biológico e Integrado contra os Animais e Plantas Nocivas OILB (BRASIL, 2002).

O modelo de certificação da PIF segue a certificação voluntária. Para obter o certificado, os produtores que comprovarem ter experiência em produção integrada de, no mínimo, um ciclo agrícola poderão aderir ao sistema e serem avaliados por meio de Organismos de Avaliação de Conformidade (OAC), que são instituições independentes de terceira parte, credenciada pelo Inmetro. Uma vez avaliada e considerada como realmente praticante da tecnologia PIF, a 
propriedade recebe um selo de conformidade da fruta, contendo a logomarca PIF Brasil e a chancela do Mapa/Inmetro (CONCEIÇÃO, BARROS, 2005).

Neste sentido, para atender ao objetivo proposto neste trabalho, utilizou-se do mecanismo utilizado pelos órgãos avaliadores no tocante aos critérios, porém diferindo no procedimento. Desta forma neste trabalho apenas aplicou-se a lista de verificação para auditoria de acompanhamento de campo com os seus itens, requisitos e critérios tanto para a atividade no campo, quanto para a atividade pós-colheita. A lista de verificação tem como referência as normas estabelecidas no programa de produção integrada de frutas estabelecidas pelo Ministério da Agricultura.

A lista de verificação é composta de duas partes: Auditoria de Acompanhamento no Campo e Pós-Colheita. A Tabela 2 e 3 relaciona para cada item da norma, a quantidade de requisito e os critérios para a auditoria de campo e auditoria pós-colheita.

Tabela 2 - Número de itens relacionados na lista de verificação para Auditoria de Acompanhamento no Campo

\begin{tabular}{|c|c|c|c|c|}
\hline \multicolumn{2}{|l|}{ Número de itens da Norma } & \multicolumn{3}{|c|}{ Critérios } \\
\hline Item da Norma & Requisitos & Recomendadas & Obrigatórias & Proibidas \\
\hline 1. Capacitação & 20 & 17 & 3 & - \\
\hline 2. Organização de Produtores & 1 & 1 & - & - \\
\hline 3. Recursos Naturais & 4 & 4 & - & - \\
\hline 4. Material Propagativo & 2 & 2 & - & - \\
\hline 5. Implantação de Pomares & 3 & 3 & - & - \\
\hline 6. Nutrição de Plantas & 7 & 6 & 1 & - \\
\hline 7. Manejo do Solo & 4 & 2 & 2 & - \\
\hline 8. Irrigação & 3 & 3 & - & - \\
\hline 9. Manejo da Parte Aérea & 8 & 4 & 3 & 1 \\
\hline 10. Proteção Integrada da Planta & 23 & 17 & 4 & 2 \\
\hline 11. Colheita e Pós-Colheita & 19 & 12 & 6 & 1 \\
\hline 12. Análise de Resíduos & 4 & 3 & - & 1 \\
\hline 13. Processos de Empacotadoras & 4 & 4 & - & - \\
\hline $\begin{array}{l}\text { 14. Sistema de Rastreamento e } \\
\text { Auditorias }\end{array}$ & 10 & 6 & 4 & - \\
\hline 15. Assistência Técnica & 2 & - & 2 & - \\
\hline TOTAL & 114 & 84 & 25 & 5 \\
\hline
\end{tabular}

Tabela 3 - Número de itens relacionados na lista de verificação para Auditoria de Acompanhamento Pós-colheita

\begin{tabular}{|c|c|c|c|c|}
\hline \multicolumn{2}{|l|}{ Número de itens da Norma } & \multicolumn{3}{|c|}{ Critérios } \\
\hline Item da Norma & Requisitos & Recomendadas & Obrigatórias & Proibidas \\
\hline 1. Capacitação & 12 & 2 & 10 & - \\
\hline 2. Organização de Produtores & 1 & 1 & - & - \\
\hline 11. Colheita e Pós-Colheita & 15 & 3 & 10 & 2 \\
\hline 12. Análise de Resíduos & 4 & - & 3 & 1 \\
\hline 13. Processos de Empacotadoras & 10 & 4 & 4 & 2 \\
\hline $\begin{array}{l}\text { 14. Sistema de Rastreamento e } \\
\text { Auditorias }\end{array}$ & 8 & 1 & 7 & - \\
\hline 15. Assistência Técnica & 1 & - & 1 & - \\
\hline TOTAL & 51 & 11 & 35 & 5 \\
\hline
\end{tabular}

Na tabela 2, a numeração segue, conforme estabelecido na norma. 
Das regiões produtoras de maça no Estado do Paraná, a pesquisa foi realizada precisamente no município de Porto Amazonas com dois produtores e no município de Palmeira, com um produtor. Vale ressaltar que os produtores além de maça produzem outras frutas. Para a aplicação da lista de verificação foram realizadas visitas nas unidades produtoras, quando foram realizadas entrevistas com os responsáveis técnicos de cada empresa, quando os mesmos responderam aos itens relacionados nas listas de verificação. Ressalta-se também que as listas de verificação foram extraídas de INMETRO (2009). Sua aplicação ocorreu no período de 22/04/2009 a 20/05/2009.

Os resultados serão apresentados também em duas partes: a primeira na Tabela 4 diz respeito à Lista de Verificação para Auditoria de Acompanhamento no Campo e a segunda parte na Tabela 5 diz respeito a Lista de Verificação para Auditoria de Acompanhamento Pós-colheita,

Tabela 4 - Resultado da aplicação em \% da Lista de Verificação para Auditoria de Acompanhamento

\begin{tabular}{|l|c|c|c|}
\hline \multirow{2}{*}{ Item da Norma } & \multicolumn{3}{|c|}{ Pomares - \% de Acertos } \\
\cline { 2 - 4 } & $\mathbf{A}$ & $\mathbf{B}$ & $\mathbf{C}$ \\
\hline 1. Capacitação & 95 & 85 & 60 \\
\hline 2. Organização de Produtores & 100 & 100 & 0 \\
\hline 3. Recursos Naturais & 100 & 75 & 0 \\
\hline 4. Material Propagativo & 100 & 100 & 100 \\
\hline 5. Implantação de Pomares & 100 & 100 & 66,67 \\
\hline 6. Nutrição de Plantas & 100 & 100 & 85,71 \\
\hline 7. Manejo do Solo & 100 & 100 & 100 \\
\hline 8. Irrigação & 66,67 & 100 & 33,33 \\
\hline 9. Manejo da Parte Aérea & 100 & 100 & 37,5 \\
\hline 10. Proteção Integrada da Planta & 100 & 91,3 & 86,96 \\
\hline 11. Colheita e Pós-Colheita & 94,74 & 73,68 & 63,16 \\
\hline 12. Análise de Resíduos & 100 & 75 & 25 \\
\hline 13. Processos de Empacotadoras & 100 & 100 & 25 \\
\hline 14. Sistema de Rastreamento e Auditorias & 100 & 60 & 20 \\
\hline 15. Assistência Técnica & 100 & 100 & 100 \\
\hline TOTAL & $\mathbf{9 7 , 0 9 \%}$ & $\mathbf{9 0 , 6 7 \%}$ & $\mathbf{5 3 , 5 6 \%}$ \\
\hline
\end{tabular}

Tabela 5 - Resultado da aplicação em \% da Lista de Verificação para Auditoria de Acompanhamento Pós-Colheita

\begin{tabular}{|l|c|c|c|}
\hline \multirow{2}{*}{ Item da Norma } & \multicolumn{3}{|c|}{ Pomares - \% de Acertos } \\
\cline { 2 - 4 } & A & B & C \\
\hline 1. Capacitação & 91,67 & 100 & 75 \\
\hline 2. Organização de Produtores & 100 & 100 & 0 \\
\hline 11. Colheita e Pós-Colheita & 100 & 80 & 40 \\
\hline 12. Análise de Resíduos & 100 & 50 & 25 \\
\hline 13. Processos de Empacotadoras & 90 & 100 & 30 \\
\hline 14. Sistema de Rastreamento e Auditorias & 87,5 & 37,5 & 12,5 \\
\hline 15. Assistência Técnica & 100 & 100 & 0 \\
\hline TOTAL & $\mathbf{9 5 , 6 0 \%}$ & $\mathbf{8 1 , 0 7 \%}$ & $\mathbf{2 7 , 2 1 \%}$ \\
\hline
\end{tabular}

A Figura 3 ilustra os resultados apresentados nas Tabelas 4 e 5.

Figura 3 - Resultado da aplicação da lista de verificação no campo e pós-colheita para as três unidades produtivas pesquisadas. 


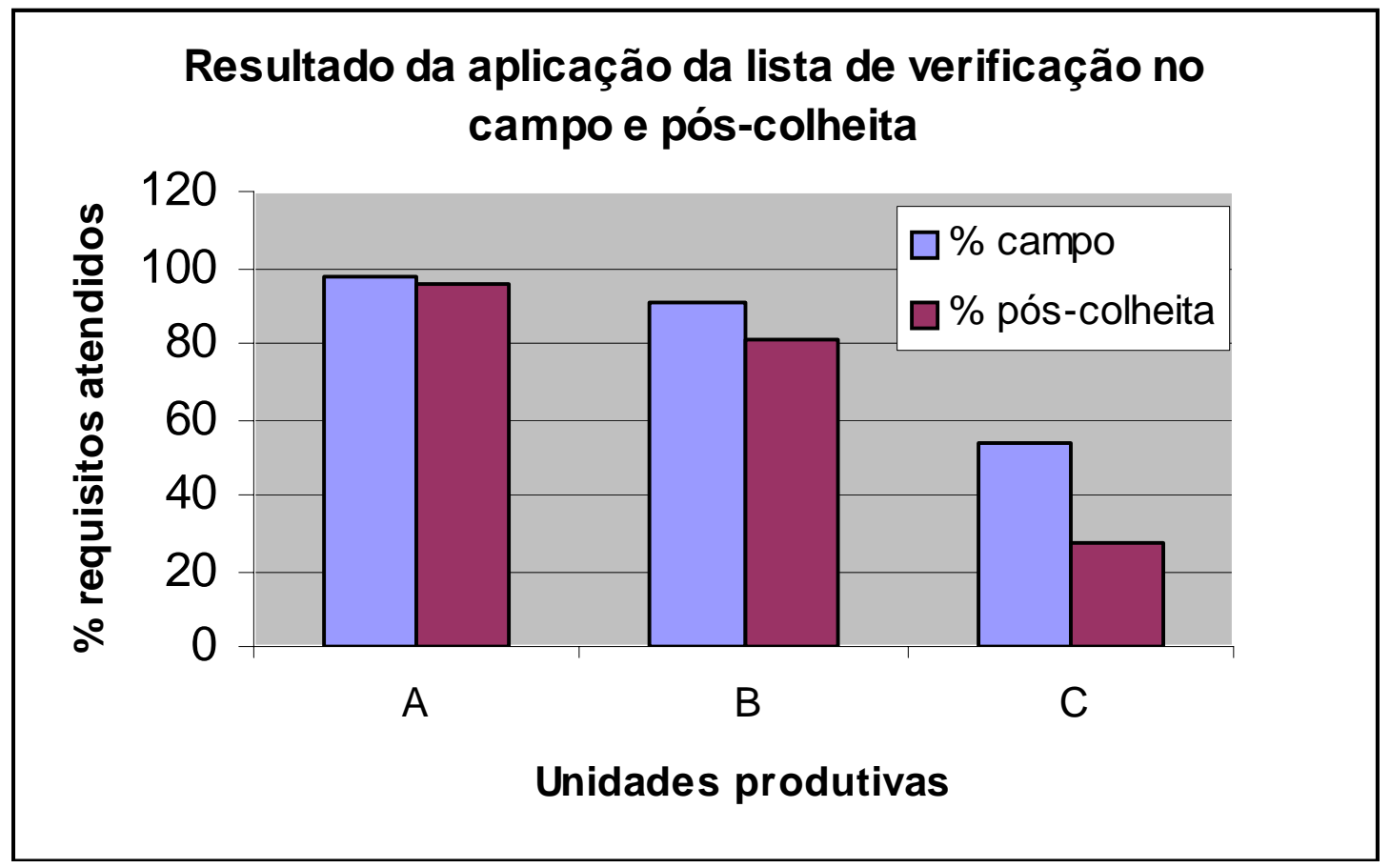

\section{Conclusão}

Há três produtores de maçã no município de Porto Amazonas. Todos eles produzem outras frutas além da maçã. Os produtores A e B possuem a sede no próprio município junto à propriedade, e o produtor $\mathrm{C}$ na cidade de Palmeira tendo também propriedades no Rio Grande do Sul, Goiás e no Distrito Federal.

Os produtores da região são proprietários que continuaram o trabalho de seus antecedentes. Um dos produtores sobrevive apenas dos pomares; outro possui outra profissão, mas mantêm o pomar por hobby; e o outro faz parte de um grupo industrial, o qual comercializa fertilizantes, equipamentos agrícolas.

Os resultados obtidos demonstram que o pomar A atende o maior número de requisitos para obter o selo de qualidade da PIM. Este fato está relacionado às iniciativas de exportação pois o produtor já exporta outras frutas para a Europa com o selo de Produção Integrada, também já exportou maçã, mas não nos dois últimos anos.

Os produtores B e C, ainda necessitam de ajustes em seus processos produtivos para serem inseridos no conceito de Produção Integrada de Frutas, porém não significa com estes resultados que os mesmos não produzem frutas de qualidade, apenas que os procedimentos para obtenção de tal modelo ainda não está completamente estruturado.

\section{Agradecimentos}


Agradecimentos especiais aos proprietários das unidades produtoras de maçãs que permitiram a realização da pesquisa e aos gerentes que prontamente colaboraram com as respostas da lista de verificação.

\begin{abstract}
The pomiculture is a relatively recent activity in Brazil. It started in the 70's decade with incentives and support for research and extension. Currently, the worldwide consumption of apple "in natura" has shown a preference for consuming fruits with good appearance, size and uniformity and other aspects of flavors, food safety, the protection of the environment and traceability. Therefore, the INMETRO together with the Ministry of Agriculture, Livestock and Supply, developed a program of assessment conformity, it's a voluntary program that generates fruit with high-quality, giving priority to sustainability, the use of natural resources, the replacement of polluting inputs, monitoring procedures and the traceability of the whole process of the program, making it economically viable, environmentally appropriate and socially fair. This work describes the situation of the productive chain of apple in the city of Porto Amazonas in the state of Paraná. After the tabulation of data concludes that there are a difference between farmers with respect the deployment of Integrated Apple Production. This paper describes the situation of the productive chain of the apple in the city of Porto in the Amazon state of Paraná. After the tabulation of the data we can conclude that there is a difference between farmers with respect to the deployment of Integrated Apple Production (IMP), considering that the producer of the orchard A is the one that are most in accordance to certification of Integrated Production apple. Producers B and C, are not yet ready to be inserted in the concept of Integrated Fruit Production.
\end{abstract}

Keywords: apple, sustainability, traceability, food safety and integrated production.

\title{
Referências bibliográficas
}

ANDRIGUETO, José R. e KOSOSKI, Adilson R. Desenvolvimento e Conquistas da Produção Integrada de Frutas no Brasil. 2003. Disponível em

< http://www.cnpuv.embrapa.br/tecnologias/pin/pdf/p_01.pdf >. Acesso em: 02 jun. 2009.

ANDRIGUETO, José R.; KOSOSKI, Adilson R. Desenvolvimento e Conquistas da Produção Integrada de Frutas no Brasil - até 2004. 2005. Disponível em http://www.inmetro.gov.br/qualidade/relatorio2005.doc > Acesso em: 15 jun. 2009.

ANDRIGUETO, José R.; KOSOSKI, Adilson R. O sucesso da Produção Integrada. 2009. Disponível em < http://www.cnpat.embrapa.br/frutas/boletins/Boletim1/boletim11.htm >. Acesso em: 15 jun. 2009.

AZEVÊDO, Cláudio Luiz L. A aplicação dos documentos de acompanhamento na Produção Integrada de Citros na Bahia. 2009. Disponível em < http://www.cnpmf.embrapa.br/pic_bahia/aplicacao_documentos.pdf >. Acesso em: 15 jun. 2009.

BRDE - Banco Regional de Desenvolvimento de Extremo Sul. Cadeia Produtiva da Maçã - Produção, armazenagem, comercialização, industrialização e apoio do BRDE na Região Sul do Brasil. 2005. Disponível em < http://www.brde.com.br/estudos_e_pub/ES\%202004-01\%20Cadeia\%20Produtiva\%20da\%20Ma\%C3\%A7a.pdf $>$. Acesso em: 16 mai. 2009.

FERREIRA, Paula. Yes, nós temos maçãs. 2009. Disponível em < www.finep.gov.br/imprensa/revista/edicao5/inovacao_em_pauta_5_pag43a47_macas.pdf >. Acesso em: 04 jun. 2009.

INMETRO. Produção Integrada de Frutas $\quad$ - PIF. 2009. Disponível em < http://www.inmetro.gov.br/credenciamento/organismos/pif.asp\#maca >. Acesso em: 16 mai. 2009.

MARTONI, Ligia. Tempo instável prejudica safra de maçã. 2008. Disponível em <http://www.paranaonline.com.br/editoria/economia/news/160902/>. Acesso em: 15 jun. 2009. 
BRASIL - 2002 - Ministério da Agricultura, Pecuária e Abastecimento. Marco Legal da Produção Integrada de Frutas do Brasil. 2002. Disponível em < http://www.agricultura.gov.br/ >. Acesso em: 15 jun. 2009.

BRASIL - 2006 - Ministério da Agricultura, Pecuária e Abastecimento Aprova as Normas Técnicas Específicas para a Produção Integrada de Maçã - NTEPI - Maçã. Disponível em < http://extranet.agricultura.gov.br/sislegisconsulta/servlet/VisualizarAnexo?id=11962>. Acesso em: 15 jun. 2009.

BRASIL - 2007 - Ministério da Agricultura, Pecuária e Abastecimento. Projeto vai divulgar qualidade e sanidade da maçã. Disponível em < http://www.criareplantar.com.br/noticia/ler/?idNoticia=8475 >. Acesso em: 16 mai. 2009.

CONCEIÇÃO, Júnia Cristina P. R. da.; BARROS, Alexandre, L. M. Texto para Discussão No 1122: Certificação e Rastreabilidade no Agronegócio: Instrumentos cada vez mais necessários. 2005. Disponível em < www.ipea.gov.br/pub/td/2005/td 1122.pdf > . Acesso em: 02 jun. 2009.

OLIVEIRA, Vitor H. de. Produção Integrada de Frutas: conceitos básicos. 2009. Disponível em < http://caju.cnpat.embrapa.br/pif/Publicacoes/Apostila_PIF.pdf>. Acesso em: 15 jun. 2009

PAULINO, Sônia R.; JACOMETI, Wagner A. Certificação EurepGAP no Sistema Agroindustrial do Limão Tahiti. 2008. Disponível em < www.sober.org.br/palestra/9/787.pdf > . Acesso em: 02 jun. 2009

SANHUEZA, Rosa Maria V. Produção Integrada de Maçãs no Brasil. Importância da cultura. 2003. Disponível em < http://sistemasdeproducao.cnptia.embrapa.br/FontesHTML/Maca/ProducaoIntegradaMaca/index.htm >. Acesso em: 16 mai. 2009

SANHUEZA, Rosa Maria V. História da Produção Integrada de Frutas no Brasil. 2008. Disponível em < http://www.cnpuv.embrapa.br/publica/artigos/historia.html >. Acesso em: 01 jun. 2009.

SANHUEZA, Rosa Maria V., Hoffmann, A. Produção Integrada de Maça. In: Produção Integrada no Brasil. Agropecuária sustentável. Alimentos seguros. Ministério da Agricultura, Pecuária e Abastecimento. Secretaria de Desenvolvimento Agropecuário e Cooperativismo. Departamento de Sistemas de Produção e Sustentabilidade. Coordenação-Geral de Sistemas de Produção Integrada. Disponível em http://www.agricultura.gov.br> Acesso em: 02 jul. 2009.

SILVEIRA, Eliana C. Qualidade e segurança alimentar com as boas práticas na pecuária de corte. 2006. Disponível em < http://www.embrapa.br/imprensa/noticias/2006/foldernoticia.2006-07-03.1126368809/noticia.200607-27.4215958234/ >. Acesso em: 01 jun. 2009

UFPEL - Universidade Federal de Pelotas. Histórico da Produção Integrada de Frutas. 2009. Disponível em < http://www.ufpel.tche.br/pif/historico.htm >. Acesso em: 01 jun. 2009.

Nome completo: José Mauro Giroto

Filiação institucional: Universidade Federal Tecnológica do Paraná

Departamento: Coordenação do Curso Superior em Tecnologia de Alimentos

Função ou cargo ocupado: Professor

Titulação: Mestre

Endereço: Av. Ver. Ernani Batista Rosas, 3131, Bloco 13 Apto 11, 84015-900 Jardim Carvalho. Ponta Grossa - Paraná

Telefones para contato: (42) 99230528, (42) 99230528

e-mail: jmgiroto@utfpr.edu.br

Nome completo: Kellen Cristiane Ribeiro da Rocha

Filiação institucional: Universidade Tecnológica Federal do Parana 
Departamento: Coordenação do Curso Superior em Tecnologia de Alimentos

Função ou cargo ocupado: Acadêmica (formanda em agosto/2009)

Titulação: Graduada em Tecnologia de Alimentos

Endereço: Rua Miguel Calmon, 222, Apto 304, CEP: 84025330, Uvaranas, Ponta Grossa, Paraná, Brasil

e-mail: ke_rocha@yahoo.com.br

Nome completo: Suzana Helena Vogelaar

Filiação institucional: Universidade Tecnológica Federal do Paraná

Departamento: Coordenação do Curso Superior em Tecnologia de Alimentos

Função ou cargo ocupado: Acadêmica (formanda em agosto/2009)

Titulação: Graduada em Tecnologia de Alimentos

Endereço: Bonifacio Vilela, 136, Apto 03, 84010330, Centro, Ponta Grossa, Paraná, Brasil.

e-mail: suzie_2005@hotmail.com 